\title{
Pulse: um futuro responsável?
}

Pulse: a responsible future?

\begin{abstract}
Irene Raguenet Troccoli
Universidade Estacio de Sá

Universidade Federal Fluminense marciomabdalla@yahoo.com.br

Editor Científico Responsável Prof ${ }^{a}$. Dr ${ }^{\mathrm{a}}$. Denize Grzybovski Professora e Pesquisadora na Faculdade de Ciências Econômicas, Administrativas e Contábeis e na Universidade de Passo Fundo.

Submissão: 07/02/2011

\section{Resumo}

Este caso de ensino busca desenvolver habilidades e atitudes relevantes para a prática gerencial, assim como apoiar o profissional de ensino com material para aulas expositivas, por meio do levantamento de problemática pela qual passa uma organização de material desportivo à luz de seu ambiente de atuação. As informações para sua construção foram obtidas em pesquisa documental e por meio de experiências pessoais, incluindo-se a prestação de consultoria empresarial. São abordados os desafios de uma executiva de empresa de artigos desportivos, responsável pelo programa de redução de desperdícios, para executálo enquanto elemento importante para a imagem da marca, e que remetem aos problemas recorrentes no nível da responsabilidade social - os quais, embora claramente identificados, e até mesmo já submetidos a ações reversivas, teimam em sobreviver, não raro por fatores alheios à sua vontade. A discussão do caso é incitada por meio da exposição da visão da empresa sobre sua responsabilidade social como maior produtora de artigos desportivos do mundo e do questionamento quanto à possibilidade de ela estar devidamente posicionada em um futuro responsável.
\end{abstract}

Joyce Gonçalves Altaf Instituto Vianna Junior igaltaf@yahoo.com.br irene.troccoli@estacio.br

Marcio Abdalla

José Luiz Trinta IBMec RJ

jtrinta@ibmecrj.br

Aprovação: 21/03/2012

Palavras-chave: Imagem. Marca. Responsabilidade Social. Estratégia. Marketing. 


\begin{abstract}
This teaching case aims at developing abilities and attitudes that are relevant for the developing of managerial skills, as well as to support teachers with due material to expositive classes, through the presentation of a problem faced by a sporting gear company in the light of its acting environment. The information used in this building effort came from a documentary research and from personal experiences obtained in managerial consulting. Ones examines the challenges faced by a businesswoman who is responsible for the losses reduction program of a sporting gear company, which is important for the image of the company, and that relate to recurrent problems related to its social responsibility. The case discussion is stimulated by the vision of the company concerning its social responsibility as the world's largest sporting gears producer, and by the doubt as for it being rightly positioned in a responsible future.
\end{abstract}

Key words: Image. Brand. Social Responsibility. Strategy. Marketing. 


\section{INTRODUÇÃO}

Numa manhã, em fins de 2008, Susan Meyer, Vice-Presidente de Responsabilidade Corporativa da Pulse, na cidade de Marietta, no estado norte-americano de Ohio, olhava pela janela de sua sala a névoa densa dissipando-se sobre a sede da empresa. Refletia sobre o tamanho da tarefa que tivera à sua frente, para o atingimento das metas de seu programa de redução de desperdício - e do qual dependera seu futuro na empresa. Afinal, dois anos antes, um estudo interno na Pulse indicara que suas perdas materiais, desde aparas nas fábricas até displays nas lojas, alcançavam US\$ 800 milhões anualmente - o equivalente a 4,3\% dos US\$ 18,6 bilhões estimados para o valor da empresa naquele ano. "É dinheiro que gastamos em coisas que jogamos fora antes mesmo de chegarmos aos clientes", pensava Susan. E ela sabia que Calvin Henderson, então CEO da empresa, esperava ansiosamente pelo sucesso daquele programa. Afinal, a Pulse vinha alcançando bons resultados em iniciativas de marketing que só faziam reforçar o valor da marca. Exemplo contundente foi sua capacidade de solidificar a fidelização do segmento de clientes aficionados da prática do jogging por meio da criação de uma comunidade compartilhadora dos valores de consumo e de comportamento, propiciada pela parceria firmada com a Turnpike para a criação do Pulse + iDigPlay. Contudo a solução que Susan buscara para a redução do desperdício sobre a melhoria da imagem da Pulse fora a única humanamente possível enquanto perdurassem os problemas recorrentes da empresa no nível da responsabilidade social. Isso contribuía para lhe dar a certeza de que seu futuro na empresa estava garantido - pelo menos enquanto não houvesse nenhuma reviravolta na percepção interna e externa quanto à situação da imagem da empresa. 


\section{PERFIL DA PULSE}

A ideia de criar a Pulse surgiu de um projeto de MBA de David Stanford, quando frequentava a Escola de Gestão de Harvard. Com apenas 20 anos e um futuro promissor no atletismo, ele estava frustrado com a qualidade dos tênis de corrida disponíveis no mercado. Então, em 1964, Michael Scavo, treinador de atletismo na Universidade de Idaho, e Stanford tiveram a ideia de produzirem eles próprios um solado para os tênis, vertendo um componente de borracha numa torradeira de panquecas. Ambos resolveram, em seguida, dedicar-se ao fabrico e ao desenvolvimento de modelos que melhorassem o rendimento dos atletas de alta competição. Assim, em 1972 surgiu a Pulse, promovendo a mensagem de que todos podem ser atletas, à sua maneira e ao seu próprio nível de esforço - associação que tem sido fator crítico para a estratégia da marca. Ao longo dos anos, a empresa tem cultivado estilo de gestão altamente competitivo, com suas ações tendo passado a ser cotadas em bolsa em 1980, o que lhe propiciou rápida capitalização no mercado. Atualmente, a Pulse oferece linha de produtos para esportes em geral, tendo deixado para trás a associação apenas a uma marca de tênis - embora esses calçados continuem a ser o produto central. Criada com base no entusiasmo dos EUA pelo basquetebol e pelo jogging, a visão da Pulse traduziu-se em contratos de publicidade e em patrocínios voltados para alcançar uma audiência desportiva mais vasta, por meio do patrocínio a atletas individuais nos âmbitos do golfe, do basquete e do tênis. Porém, com a crescente saturação dos mercados do basquetebol e do jogging, a Pulse procurou novos campos desportivos, tendo-se virado para o futebol, que foi posteriormente eleito como um de seus focos principais.

Desejosa de fortalecer seu reconhecimento e sua credibilidade no mundo inteiro, tanto junto aos clientes como aos fornecedores, e de satisfazer os desejos e as necessidades de seus empregados - para assim também poder aspirar a um aumento da rentabilidade - a empresa divulga sustentar cinco princípios: inspirar, inovar, enfocar, conectar e cuidar. Por meio desses paradigmas, a marca busca transmitir os ideais da cultura norte-americana fundados em dinamismo, juventude, inovação, poder e, acima de tudo, espírito vencedor. Permeados pela cultura organizacional orientada aos clientes e aos atletas, seus empregados são selecionados e treinados para criar vantagens competitivas em todos os tipos de negócios desenvolvidos pela companhia. Assim, a construção da marca Pulse foi realizada no sentido de sugerir prestígio, qualidade elevada, durabilidade, conforto e simplicidade, apoiada no princípio de que uma marca não é só um conjunto de atributos, já que os consumidores compram os benefícios 
emocionais ou racionais que ela comporta e permite. Subjacente a isso, foram-lhe incorporados os valores de independência, de imaginação e de coragem. Assim, o desenvolvimento da empresa se norteava pelo objetivo de produzir o melhor e o mais inovador produto do mundo, que apoia os atletas no atingimento de seus potenciais.

Não por acaso, a Pulse tornou-se uma das marcas que proporciona uma identificação mais rápida e fácil em relação a seus concorrentes. Apoiada em seu logotipo facilmente identificável em qualquer ponto do mundo, com elevada qualidade técnica e com design arrojado, a empresa tem sido competente em proporcionar a seus utilizadores status e satisfação pessoal, o que naturalmente lhes facilita a fidelização.

\subsection{A parceria Pulse e Turnpike}

Consoante com sua estratégia de apostar continuamente em inovação e no desenvolvimento de novos produtos e soluções para, assim, granjear sucesso junto aos clientes e bater a concorrência, a Pulse fechou parceria com a Turnpike para uma ideia revolucionária. Tratou-se do Pulse+iDigPlay, lançado em maio de 2006, um novo conceito em apetrecho para praticantes de jogging desejosos de algo mais do que apenas um calçado de corrida e um MP3 para o fornecimento de fundo musical para esse esporte. Formado pelo conjunto de um par de tênis especialmente diferenciado e de um iDigPlay, o produto surgiu com a proposta de sofisticar os benefícios que ambos os elementos, em suas versões tradicionais, poderiam trazer ao atleta. No caso, o calçado - chamado de Pulse + Space Zig foi idealizado como o primeiro tênis projetado para "conversar" com o iDigPlay. Isto se dá conforme o calçado Pulse+ pode ser conectado ao iDigPlay nano, por meio de um apetrecho denominado de kit esportivo Pulse+iDigPlay, que inclui um sensor dentro do calçado e um receptor que se conecta ao iDigPlay. A partir dessa conexão, as informações sobre tempo, distância, calorias consumidas e velocidade do corredor são armazenadas no iDigPlay e exibidas em sua tela. Também é oferecido feedback em áudio, em tempo real, nos fones de ouvido. E, para maximizar o benefício da experiência para os usuários, foi disponibilizada uma nova seção dentro da loja virtual de música iMelody Music Shop - a Pulse Sport Music. Também está disponibilizado um novo site de serviços pessoais na página eletrônica www.Pulseplus.com, no qual, através de uma interface colorida, dinâmica e fácil, as informações do exercício podem ser carregadas, os objetivos pessoais de treinamento podem ser vistos e avaliados, e a distância, o tempo, o ritmo e as calorias queimadas podem ser 
revistos. O resultado dessa parceria entre duas marcas, que, com design e inovação, compartilham a paixão por criar produtos de consumo que oferecem experiências singulares, mudou o modo como as pessoas correm, propiciando-lhes a virtualidade de um técnico ou um personal trainer, motivando cada passo da atividade física. Não por acaso, a Pulse está planejando tornar muitos de seus principais tipos de tênis compatíveis com o Pulse+, conectando milhões de consumidores à experiência Pulse+iDigPlay.

\subsection{A fidelização}

Consciente do princípio de que a fidelização dos clientes atinge seu estado mais sólido conforme estes passam a desejar fazer parte de um grupo emocionalmente envolvido com o produto ou serviço, a Pulse não titubeou: lançando mão das facilidades trazidas pela internet, em seu endereço eletrônico www.Pulseplus.Pulse.com, ela criou espaço especialmente dedicado à interação dos membros daquilo que chama de Comunidade. Nesse local, os "usuários Pulse+" visualizam as equipes de corredores já constituídas, podendo também “constituir" sua própria equipe; podem participar de fóruns de discussão; adentram o Clube da Distância (em que marcos, que vão de 250 a 16 mil km, são selecionados para serem alcançados, num desafio crescente aos participantes); e obtêm o status on line da performance de todos os corredores e equipes que fazem parte da comunidade, acrescido de um contador atualizado também em tempo real com o somatório de todos os quilômetros percorridos. $\mathrm{Na}$ esteira dessa iniciativa, a comunidade Pulse + se solidificou, a ponto de ter gerado a comunidade Orkut Desafios Pulse+iDigPlay - Pulseplus, cuja descrição é "Comunidade para usuários do sistema Pulse+iDigPlay/Pulse Sportband - Pulseplus divulgarem seus nomes e participarem dos diversos desafios e trocarem informações".

\subsection{A visão da responsabilidade corporativa}

Nos últimos anos, a Pulse tem-se esforçado para melhorar seu desempenho no quesito de sustentabilidade, buscando aplicá-lo não só à confecção, como à venda de seus produtos. Como exemplo, no segmento de design de novos produtos, ela adotou o procedimento de qualificar cada nova proposta de acordo com um "índice de sustentabilidade", que visa à eliminação de desperdícios e de uso de substâncias tóxicas, tais como o desenvolvimento de programas de administração de dejetos nas fábricas terceirizadas e a redução de colas 
derivadas de petróleo. O maior exemplo do compromisso da empresa com esse princípio é seu grupo de designers de produtos chamado de "Formatado", um think tank, cujo objetivo é disseminar um caráter cultural e social de design sustentável em todas as categorias de produtos Pulse. E foi exatamente isso que a empresa conseguiu ao lançar seu modelo de tênis Air Spinning ZZ5, em janeiro de 2008: além do impacto altamente favorável junto ao público consumidor enquanto instrumento para a prática do basquete, o calçado obteve elevada pontuação no "índice de sustentabilidade", ao usar materiais reciclados e processo de colagem novo e menos tóxico. Mas a empresa está ciente de que esse compromisso com a sustentabilidade não pode ser cumprido apenas pontualmente, como no caso dos produtos top de linha ou dos lançamentos recentes, exemplo do Air Spinning ZZ5. O objetivo maior é que toda a linha de produção usufrua desses benefícios. Trata-se de tarefa nada fácil, considerando-se que os modelos mais populares - e que desfrutam de preço inferior a US\$ 75 - são responsáveis pela maior porcentagem de volume das vendas anuais totais, chegando a 40 milhões de pares. Afinal, enquanto empresa de bens de consumo que compartilha da certeza de que seu sucesso estará garantido se sua marca conseguir ocupar espaço relevante na mente de seus clientes, assim como do desejo de que isto aconteça, a Pulse sabe que criar uma imagem de marca não é tarefa fácil. Isto porque esta precisa ser construída de forma a traduzir um conjunto simplificado de percepções e de associações mentais - mais ou menos instáveis ligadas ao produto ou serviço referido ou à organização que os oferece. No caso da Pulse, esse patrimônio foi construído sob diversas dimensões e valores relativos à sua imagem, com destaque para o desporto (domínio da atividade da marca), a nacionalidade norte-americana (a origem da marca) e a qualidade (associada à sua utilização por personalidades altamente conceituadas no mundo do desporto). Por outro lado, a empresa também tem consciência de sua vulnerabilidade a juízos de valor. Assim é que, para alguns consumidores, a marca Pulse possui imagem muito positiva, associada a bom desempenho na competição ao mais alto nível e facilmente reconhecível em qualquer parte do mundo - o que se traduz no sucesso da criação da comunidade dos usuários do Pulse+iDigPlay. Para outros consumidores, porém, a marca Pulse está associada à exploração do trabalho infantil e a todos os malefícios daí decorrentes. 


\subsection{O problema da responsabilidade social}

Em que pese a Pulse ter tido sucesso em gerar a fidelização a seu tênis de corrida por meio da criação do desejo do compartilhamento de valores de consumo e de comportamento dos usuários, um fardo teima em permanecer sobre a empresa: a publicidade negativa que há tempos ronda as condições de trabalho da mão-de-obra terceirizada que contrata, localizada em países em desenvolvimento. Não por acaso, em 1998 o fundador e então CEO da empresa, Calvin Henderson, admitia publicamente que "O produto Pulse tornou-se sinônimo de salários aviltantes, de sobrecarga forçada de trabalho e de exploração humana". Já naquela época a Pulse envidava esforços consistentes para melhorar essa situação, investindo em programas de monitoramento dos terceirizados: ela passou a enviar auditores, incluindo observadores de fora da empresa, às fábricas subcontratadas para a verificação in loco das condições de trabalho, tentando obter destas o compromisso de atendimento a seu código de conduta. Consequentemente, em 2005 a empresa tornou-se a primeira de sua indústria a divulgar os nomes e as localizações de suas fábricas no site www.Pulseresponsability.com, como forma de demonstrar transparência e de estimular seus competidores a juntarem-se na busca dessas melhorias. Trata-se de iniciativa louvável, considerando-se que, atualmente, a força de trabalho empregada pela empresa alcança nada menos que 800 mil trabalhadores em 52 países.

Os resultados, contudo, não parecem ter sido tão bons como a empresa esperava. Em 2005, a Pulse solicitou auditoria social ao professor John Locke, da Universidade de Chicago, que, no ano seguinte, lançou seu veredicto: apesar de "[...] significantes esforços e investimentos da Pulse [...] as condições de trabalho em quase $80 \%$ de seus fornecedores permaneceram as mesmas ou pioraram". Esse diagnóstico provou ter fundamento quando, em meados de 2008, um repórter da TV australiana expôs as condições aviltantes que imperavam em uma fábrica malaia de camisetas repleta de trabalhadores imigrantes, forçados a habitarem alojamentos superlotados e imundos, e cujos passaportes tinham sido retidos pelo empregador até eles terem saldado as "taxas" devidas aos recrutadores. Ao ir ao ar, o programa mostrou que as paredes da fábrica estavam tomadas por banners com o símbolo da Pulse. A empresa reagiu a esse escândalo admitindo publicamente violações a seu código de conduta, reembolsando os prejuízos dos trabalhadores e assumindo os custos de suas realocações.

Não há dúvida de que esses acontecimentos encontram suas raízes nos controles deficientes dos governos dos países envolvidos. Em última instância, isso implica que cabe às 
marcas a tarefa de policiarem seus fornecedores - tarefa praticamente impossível para a Pulse, que produz 98\% de seus calçados em fábricas chinesas, vietnamitas, indonesianas e tailandesas e estima que $80 \%$ desses trabalhadores se constituam de mulheres entre 18 e 24 anos de idade, com baixa escolaridade e com pouca especialização. A Pulse está consciente das consequências funestas que essa situação implica, mas, ao mesmo tempo, está decidida a não abrir mão da terceirização, que, por sinal, apresenta variados graus no impacto da reputação. Isso porque a empresa trabalha com vários modelos de contrato de fornecimento, dependendo do tempo da relação entre o fornecedor e a Pulse, ou de quanto da receita do fabricante provém apenas da Pulse. No caso da manufatura de calçados, por exemplo, a empresa transaciona com cerca de 40 fornecedores, muitos dos quais já são seus parceiros de longa data e que desfrutam de grande proximidade com os designers da Pulse ao longo de todo processo de produção. Já no caso dos outros itens, a Pulse possui contratos de curto prazo com muitos mais fornecedores, o que implica influência muito limitada sobre o dia-adia desses últimos. Assim é que, mesmo que os códigos de conduta sejam restritos, eles acabam sendo atropelados à medida que prazos apertados de entrega colocam grande pressão sobre os resultados: pressionar por horas extras ou por cancelamentos de folgas passa a ser a única saída para o atendimento de uma revisão de última hora no prazo de entrega de uma encomenda.

Em que pesem esses problemas, a Pulse tem buscado soluções alternativas. Uma delas é a substituição das linhas de produção desorganizadas e de baixa produtividade em processo manufatureiro enxuto e eficiente por meio da organização dos trabalhadores em grupos multitarefas. A lógica por trás da sustentabilidade desse modelo reside em ele exigir mais treinamento, o que pode motivar os donos das fábricas a melhorarem as condições de trabalho para evitarem a perda de mão-de-obra mais qualificada. Outra iniciativa foi a adoção de classificação social em suas fábricas, em escala que vai de A a D, e a realização de auditorias periódicas para a classificação do desempenho verificado. Na auditoria realizada em 42 delas, no ano fiscal 2006, apenas sete conseguiram grau A. Já 13 obtiveram grau D devido a transgressões, como salários abaixo do mínimo devido ou jornadas de 14 dias de trabalho sem folgas.

Isto tudo fez com que Susan Meyer se perguntasse se a Pulse não deveria ter uma postura muito mais ambiciosa em seu programa de redução do desperdício, enquadrando-o numa visão maior, a ser disseminada globalmente, de que não desperdiçar ultrapassa as fronteiras do descarte material, alcançando o resgate das perdas aplicadas à própria dignidade 
humana. Sua reflexão remetera a seu desafio de contribuir para a melhoria da imagem da Pulse enquanto socialmente responsável - e, por tabela, ajudar a não esvaziar iniciativas de sucesso, como a parceria com a Turnpike - de estar ameaçado pela incapacidade, verificada desde a década anterior, e de a empresa alterar as sofríveis condições de trabalho da mão-deobra recrutada em países asiáticos. Era-lhe inaceitável que a fidelização dos clientes da Pulse estivesse sendo erodida pela questão da imagem social. Por isso mesmo, ela se dispusera a trazer esse ponto para discussão junto a seus superiores da alta direção. Afinal, ela reportavase diretamente ao CEO Calvin Henderson, comandava um time de 135 pessoas distribuídas pelo mundo, e seu trabalho implicava garantir que todas as áreas estivessem impregnadas do conceito de responsabilidade social. Susan acreditava que poderia atingir essa meta conforme conseguisse a transformação de seu departamento em um laboratório de ideias que pudesse ajudar a prever riscos e a garantir inovações. Mas ela sabia que não bastaria apenas trazer o ponto a discussão, pois os elementos-chave dessa situação já eram conhecidos por seu superior. $\mathrm{O}$ que ele iria querer seriam sugestões criativas sobre o que fazer e como fazer. Além do mais, ela sabia que seu futuro na empresa dependia de seu desempenho na resolução desse problema: Henderson já a havia chamado para uma conversa a portas fechadas e sinalizado que seria muito difícil mantê-la no cargo caso o desenlace não fosse positivo para a Pulse.

\subsection{A solução proposta}

Embalada nessa pressão, Susan Meyer tomara uma decisão ousada, que passava pelo uso do peso da Pulse na economia norte-americana para envolver autoridades governamentais dos EUA. Ela solicitara os serviços do escritório de lobby empresarial Managerial Consulting para convocar deputados e senadores sensíveis à causa social a sentarem-se lado a lado com a Pulse para elaborarem o que seria o Conjunto de Normas Contratuais do Trabalho de Terceirizados - CNCTT. Essas normas, cujas linhas gerais o Managerial Consulting já havia elaborado em conjunto com entidades representativas dos interesses dos trabalhadores de países em desenvolvimento, cobririam todos os assuntos relativos à segurança, à idade, à remuneração e à carga de trabalho dos terceirizados. Simultaneamente, o Managerial Consulting já havia alinhavado os primeiros contatos com entidades representativas dos países envolvidos nesse assunto para que todos aceitassem o novo protocolo de procedimentos do CNCTT, obedecendo-lhe sempre que se tratasse de países menos desenvolvidos empregarem 
ou executarem serviços terceirizados de países mais desenvolvidos. Ou seja, com essa decisão, Susan estava certa de que a Pulse não só estaria caminhando para resolver um problema interno como também estaria lançando-se, pioneiramente e com alcance mundial, como a grande incentivadora de uma mudança radical no modo de pensar o lucro empresarial. Sem dúvida, essa iniciativa pioneira teria o potencial de trazer à Pulse dividendos inestimáveis à imagem de sua marca, assim como de garantir sua permanência como VP - e quiçá, em sendo bem-sucedida, de obter-lhe não só a garantia de seu emprego como até a tão sonhada promoção.

\section{Questões para discussão}

1) Quanto aos cinco princípios sustentados pela Pulse (inspirar, inovar, enfocar, conectar e cuidar), em que medida as ações adotadas têm sido coerentes com tais princípios?

2) Como você classifica a meta de fidelização (lealdade) pretendida, a partir da criação da comunidade Pulse + ?

3) Caso você estivesse na posição de Susan Meyer, preocupada com o valor da marca Pulse, de que outra forma você sugeriria que a Pulse tratasse a questão da terceirização da mão-deobra junto à opinião pública?;

4) Você entende que o posicionamento da Pulse quanto ao trabalho escravo não é um problema de responsabilidade social dela mas sim dos controles deficientes dos governos dos países envolvidos? Por quê?

5) Até aonde deve ir a responsabilidade social da empresa sem que se criem fricções políticas, tendo em vista que seus fornecedores periféricos estão em dia com as (fracas) exigências dos governos locais?

6) Quais os riscos para Susan Mayer e para a Pulse caso a iniciativa com o governo norteamericano fracassasse, principalmente em termos das reações dos competidores e dos investidores?

7) Até que ponto as ações de reversão da exploração da mão-de-obra terceirizada em terceiros países seriam visíveis para os clientes da Pulse, e quais os impactos para a construção da reputação da empresa? 


\section{SÍNTESE DAS NOTAS DE ENSINO}

\section{a) Área(s) de conhecimento(s) a que se destina o caso}

O caso se destina à área de Marketing e Estratégias Empresariais

\section{b) Objetivos pedagógicos}

Considerando-se as três dimensões - analítica, conceitual e de apresentação propostas pelo modelo denominado Case Difficulty Cube, defendido por Leenders e Erskine (1987) e que contemplam o desenvolvimento de um caso, verifica-se que o caso apresentado enquadra-se no chamado nível $\mathbf{2}$ da dimensão analítica. Tal enquadramento se justifica pelo fato de o caso proporcionar ao estudante possibilidades de decisão distintas das tomadas por seu protagonista. Em relação à dimensão conceitual, pode-se dizer que o caso também é compatível com o nível 2 , pois, embora os conceitos possam ser claramente entendidos pelos estudantes após cuidadosa leitura - característica do nível 1, o tema é contraditório e polêmico sob o ponto de vista de alguns autores, porque ainda não há consenso acerca das definições de marketing social. O caso ainda exige conhecimentos simultâneos e de relativa complexidade que o leitor deverá trazer consigo como pré-requisito a seu estudo, como aqueles relativos às estratégias de formação de parcerias entre players tradicionalmente situados em áreas de atuação diversas e nem sempre congruentes, tendência muito em voga no meio empresarial.

Finalmente, no que tange à dimensão de apresentação, verifica-se que o caso também pertence ao nível 2, em função de sua relativa extensão de leitura. Ele ainda apresenta informações relevantes não concentradas em um único ponto do texto, ou seja, exige uma leitura atenta por parte do analista. Embora se verifique um esforço em se organizarem as informações, observa-se que, na realidade existente no mundo prático, elas muitas vezes encontram-se espalhadas pela linha do tempo, ou mesmo pelos diversos departamentos da organização. Como ressalta Roesch (2006, p. 10), "O caso de ensino retrata situações ou problemas reais que requerem soluções por parte dos gestores ou de outros personagens do caso".

O caso tem por premissa abordar as temáticas: estratégia de marketing; fidelização do cliente; marketing social; responsabilidade social; brand equity e cultura organizacional. Ressalta-se que a não inclusão da teoria como elemento textual do caso baseou-se nos pressupostos de Mascarenhas et al. (2007), que indicam que o aluno ao qual se destina domina as teorias e disciplinas que envolvem a narrativa. Ademais, trata-se de formato mais 
desafiador, já que incita o aluno à reflexão dos aspectos organizacionais que ligam a teoria à prática.

O caso apresentado possibilita ao leitor colocar-se no lugar do tomador de decisões ou do solucionador de problemas. Em especial, ele provoca o estudante a fazer uso de teorias implícitas, analisando-as e colocando-as em prática, de modo a proporcionar o melhor resultado para a empresa.

\section{c) Público-alvo}

O caso de ensino apresentado é preferencialmente destinado a alunos de cursos de pósgraduação lato sensu e stricto sensu de Administração de Empresas. Entretanto pode ser também aplicado em cursos de graduação desta área, desde que respeitadas algumas limitações de seus alunos, por exemplo, modificando-se o grau de dificuldade das questões ou não as aplicando em sua integralidade. 


\section{ESTRATÉGIA DE ENSINO}

\subsection{Alternativas para análise do caso}

Para a análise deste caso, aconselha-se o emprego de uma hora e meia, levando-se em consideração uma leitura prévia por parte da turma, com vistas à melhor compreensão do assunto. Previamente ao debate, devem ser formados grupos com não mais que quatro integrantes, de maneira que os alunos exponham seus pontos de vista e persigam um consenso. Tal tarefa deverá ter tempo médio de 30 minutos. Em seguida, o professor poderá propor que a turma se disponha na formação de um círculo e, em seguida, inicie provocando e mediando as opiniões. Essa etapa deverá durar cerca de 30 minutos. Ao final, o professor deverá realizar um fechamento, gastando tempo médio de 30 minutos. Nesta etapa, o professor poderá tecer comentários em relação às decisões adotadas pelos membros do debate, fazendo uma ligação entre tais propostas e os pontos-chave da teoria.

\subsection{Conceitos teóricos}

a) Marketing, segundo autores como Richers (1978), é um sistema administrativo que, por meio de um planejamento estratégico, procura conhecer as necessidades dos mercados-alvo e atender a elas com a oferta de produtos ou serviços adequados a essas necessidades, tendo como resultado a possibilidade de atingir os objetivos da organização. A segmentação, nesse caso, é a base de toda a estratégia de marketing. Primeiro se segmenta o mercado em grupos homogêneos de consumidores, escolhem-se aqueles grupos que oferecem melhores condições para serem atendidos com o tipo de serviço ou o produto em que a organização é - ou pretende ser - especializada, de modo a atender às necessidades e aos desejos desses grupos específicos de consumidores. Em seguida, posiciona-se o produto ou o serviço, de forma a expressar suas diferenças e seus benefícios, para, então, decidir-se estrategicamente a melhor maneira de comunicar àqueles consumidores que suas necessidades podem ser, provavelmente, mais bem atendidas por essa organização.

b) Simircich e Stubbart (1985) abordam como a teoria em estratégia empresarial tem tratado a questão dos ambientes organizacionais, e questionam a visão de que as organizações devam ser consideradas como organismos que se adaptam às demandas ambientais, uma vez que esse ambiente é interpretativamente criado pela interação dos 
gestores com os demais atores da própria organização. Pautada em uma dicotomia entre organização e ambiente, essa visão se baseia na ideia de que as organizações se inserem em ambientes organizacionais que têm existência própria, de forma objetiva e independente da organização. Ambientes nessa perspectiva são forças às quais a organização deve adaptar-se, alinhar-se ou tentar controlar.

c) Reichheld (1993) argumenta que empresas líderes em lealdade reconhecem que a lealdade do consumidor é obtida pela entrega consistente de valor superior. Estabelece que a competição baseada em fidelidade requer a compreensão e a atenção simultânea aos clientes, a oferta de produtos e de serviços, e empregados e sistemas de medição permanentes. A atenção deve ser direcionada para os consumidores certos, ou seja, aqueles passíveis de continuarem fazendo seus negócios com a empresa ao longo do tempo.

d) Kotler e Roberto (1992) definem Marketing Social como uma estratégia de mudança de comportamento. Eles combinam os melhores elementos das abordagens tradicionais da mudança social num esquema integrado de planejamento e de ação e aproveitam os avanços na tecnologia das comunicações e na capacidade de marketing.

e) Oliver (1999, p. 41) argumenta que os cinco critérios essenciais para que um produto ou serviço possa conquistar o estado de lealdade duradouro do cliente são: "Primeiro, o produto deve ser de alguma configuração única que o torna desejável (i.e. superior). Segundo, um segmento específico lucrativo dos consumidores da empresa deve achá-lo desejável dessa maneira. Terceiro, o consumível deve ser objeto de adoração, pelo menos aos olhos dos consumidores potencialmente fiéis à empresa. Quarto, o produto deve possuir a capacidade de estar inserido em uma rede social, a tal ponto que, se os consumidores da empresa não estiverem conectados, ao menos perceptivamente, eles não se sentirão como fazendo parte da vila. Quinto, a empresa deve estar predisposta a despender recursos para criar, povoar e manter a vila". Para satisfazer o primeiro critério, a empresa deve oferecer produto que possua distinção de qualidade percebida em relação a seus concorrentes e seja acessível aos consumidores potenciais. O segundo critério determina que um segmento potencialmente comprador dos produtos ou serviços da empresa se interesse pelo produto e tenha chances reais de tornar-se leal à marca. O terceiro implica que o consumidor esteja fortemente engajado no atributo de persistência individual, quando transpõe o sentimento de mera necessidade para adoração, utilizando a marca com persistência inabalável independente das propostas sedutoras que os competidores venham a oferecer. O quarto critério estabelece que a empresa possua meios para estimular os consumidores potenciais a participarem de 
reuniões com presença física, a exemplo de grupos de investidores em empreendimentos imobiliários, ou em grupos interligados pela Internet, a exemplo do Orkut. Satisfazer o último critério significa estabelecer uma interação perfeita que associe o produto a um grupo social que tenha em comum a fascinação e o compromisso incondicional com o consumo coletivo do produto.

f) Embora alguns autores utilizem os conceitos de imagem e de reputação como sinônimos, estudos recentes sobre reputação apontam duas características que os diferenciam: reputação é construída ao longo dos anos e tem como base as ações e os comportamentos da organização; já imagem tem como base percepções diversas que podem ser transitórias. Dessa forma, a imagem é uma fotografia da empresa num determinado instante e, dependendo do contexto em que se encontra a empresa naquele momento, essa imagem pode ser boa ou ruim. (NUNES; ALMEIDA, 2008).

g) A responsabilidade social corporativa pode ser entendida como uma forma de "[...] gestão que se define pela relação ética e transparente da empresa com todos os públicos com os quais ela se relaciona e pelo estabelecimento de metas empresariais compatíveis com o desenvolvimento sustentável da sociedade" (ETHOS, 2007, p. 1). Responsabilidades éticas correspondem a atividades, práticas, políticas e comportamentos esperados (no sentido positivo) ou proibidos (no sentido negativo) por membros da sociedade, apesar de não codificados em lei. Elas envolvem uma série de normas, padrões ou expectativas de comportamento para atender o que os diversos públicos com os quais a empresa se relaciona (stakeholders) consideram legítimo, correto, justo ou de acordo com seus direitos morais ou expectativas (BORINELLI; VENTURA, 2004).

h) Para Srivastava e Shocker (1991), brand equity é a resultante da força da marca adicionada ao valor da marca. A força da marca é o conjunto de associações e de comportamentos dos consumidores, dos distribuidores e da empresa controladora da marca, que permitem à marca desfrutar vantagens competitivas diferenciais e sustentáveis. $\mathrm{O}$ valor da marca é o resultado financeiro resultante da habilidade de gestão para potencializar a força da marca de ações táticas e estratégicas, em favor de lucros correntes e futuros e da diminuição dos riscos. 


\section{Referências}

BORINELLI, B.; VENTURA, E. C. F. Ética, valores e cultura: especificidades do conceito de responsabilidade corporativa. In: ASHLEY, P. A. et al. (Coord.). Ética e responsabilidade social nos negócios. São Paulo: Saraiva, 2004. p. 48-61.

ETHOS, Instituto (2009). Conceito de responsabilidade social corporativa. Disponível em $<$ http://www.ethos.org.br>. Acesso em: 20 abr. 2009.

KOTLER, P.; ROBERTO, E. L. Marketing Social: estratégias para alterar o comportamento do público. Rio de Janeiro: Ed. Campus, 1992.

LEENDERS, M.; ERSKINE, J. Case research: the case writing process. London, Ontário: University of Western Ontario, 1986.

MASCARENHAS, S. A.; SILVA E MEIRELLES, D.; MIGUEL, L.; FIGUEIREDO, V. Do Pau Brasil ao Avião: O Caso Embraer. In: ENCONTRO ANUAL DA ASSOCIAÇÃO NACIONAL DOS PROGRAMAS DE PÓS-GRADUAÇÃO EM ADMINISTRAÇÃO, 31, 2007, Rio de Janeiro/RJ. Anais... Rio de Janeiro: ANPAD, 2007.

NUNES, D. A.; ALMEIDA, A. L. C. A Comunicação como Diferencial Competitivo na Construção da Reputação Corporativa. In: ENCONTRO ANUAL DA ASSOCIAÇÃO NACIONAL DOS PROGRAMAS DE PÓS-GRADUAÇÃO EM ADMINISTRAÇÃO, 32, 2008, Rio de Janeiro/RJ. Anais... Rio de Janeiro: ANPAD, 2008.

OLIVER, R. Whence customer loyalty? Journal of Marketing, v. 63, Special Issue, p. 33-44, 1999.

REICHHELD, F. F. Loyalty-based management. Harvard Business Review, v. 71, n. 2, p. 64-73, 1993.

RICHERS, R. Marketing - uma visão brasileira. São Paulo: Negócios, 2000.

ROESCH, S. M. A. Notas sobre a construção de casos para ensino. In: ENCONTRO ANUAL DA ASSOCIAÇÃO NACIONAL DOS PROGRAMAS DE PÓS-GRADUAÇÃO EM ADMINISTRAÇÃO, 30, 2006, Salvador-BA. Anais... Rio de Janeiro: ANPAD, 2006.

SMIRCICH, L.; STUBBART, C. Strategic Management in an enacted world. Academic of Management Review, v. 10, n. 4, p. 724-736, 1985.

SRIVASTAVA, R. K.; SHOCKER, A. D. Brand equity: a perspective on its meaning and measurement. Technical Working Paper, Report N. 91-124. Cambridge: Marketing Science Institute, 1991. $35 \mathrm{p}$. 